\title{
Erosion Wear Performance of Sheep Wool Fibre Reinforced Polyester Composites
}

\author{
Manivannan J, Rajesh S, Mayandi K
}

\begin{abstract}
This research work focused on erosion performance of sheep wool reinforced polyester composites at varying wt\% of fibre content (20 wt\%, $30 w t \%$ and $40 w t \%)$. The compression moulding method is used to develop the composite plate. To investigate the wear rate of the developed composite plates, the composite plate is subjected to erosion studies. As per ASTM G76 the erosion test was done with the help of air jet erosion tester. To investigate the factors of varying wt\% of fibre, impingement angle and impact velocity of the fabricated plates. The erosion behaviour of sheep wool fibre reinforced polyester composites is evaluated at varying $w t \%$ of reinforcement $(20 \mathrm{wt} \%, 30 \mathrm{wt} \%$ and $40 \mathrm{wt} \%)$ with different impact velocities $(41 \mathrm{~m} / \mathrm{s}, 72 \mathrm{~m} / \mathrm{s}$ and $100 \mathrm{~m} / \mathrm{s})$ and at different impingement angle $\left(30^{\circ}, 60^{\circ}\right.$ and $\left.90^{\circ}\right)$. The standoff distance, time and erodent discharge rate were kept constant. Alumina oxide is used as erodent material with the size of $50 \mu m$. From the result, it is observed that increase in impingement angle increase the erosion rates. Another observation is made that addition to impact velocity, increase in wt\% of reinforcement decreases the wear rates.
\end{abstract}

Keywords : Sheep wool fibre, Polyester resin, Compression moulding, Erosion wear.

\section{INTRODUCTION}

In recent trend towards erosion wear performance of polymer composites by eroding the particle with various angles of impingement and impact velocities strike the material and damage the top surface which leads to material loss and changes in functional behaviour [1], [2]. Fibres and inorganic fillers are added in poly phenylene sulphide (PPS) which enhances the tribological properties [3], [4]. The erosive wear behaviour of fibre and particulate based polymers has not much investigated [5], [6]. Particle size, particle shape, velocity and impingement angle are some of the parameters to be consider in solid particle erosion test [7]. The friction and wear behaviour was studied in PEEK composites reinforced with fibre and particulate [8], [9]. Mahapatra et al. reported that increase in erosion rate of glass fibre reinforced composites is mostly due to impact velocity [10]. Suresh et.al studied that short fibre reinforced PEK composites with varying wt $\%$ shows ductile nature in different impact velocity and impingement angle. The erosion wear is increase with increase in $\mathrm{wt} \%$ of fibre and

Revised Manuscript Received on December 15, 2019.

* Correspondence Author

Manivannan J, Department of Mechanical Engineering, Kalasalingam Academy of Research and Education, Krishnankoil, India. Email: j.manivannan@klu.ac.in

Rajesh S*, Department of Mechanical Engineering, Kalasalingam Academy of Research and Education, Krishnankoil, India. Email: s.rajesh@klu.ac.in

Mayandi K, Department of Mechanical Engineering, Kalasalingam Academy of Research and Education, Krishnankoil, India. Email: k.mayandi@klu.ac.in

maximum at $30^{\circ}$ impingement angle [11]. Sinmazcelik and Taskıran reported that the random orientation of short fibre and mineral powder based PPS composite with changes in impingement angle and impact velocity shows semi ductile nature. The rate of erosion is maximum at $60^{\circ}$ impingement angle [12]. Srivastava studied that the erosion rate is minimum in $2 \mathrm{~g}$ wheat flour filled GFRP [13]. The erosion performance of sheep wool reinforced polyester composites has not yet reported in the literature. In this experimental work, sheep wool fibre reinforced polyester composites were selected as test specimen. The erosion performance of these composites were studied with varying wt $\%$ of reinforcement, changes in impingement angle and impact velocity as $(20$ $\mathrm{wt} \%, 30 \mathrm{wt} \%$ and $40 \mathrm{wt} \%),\left(30^{\circ}, 60^{\circ}\right.$ and $\left.90^{\circ}\right)$ and $(41 \mathrm{~m} / \mathrm{s}, 72$ $\mathrm{m} / \mathrm{s}$ and $100 \mathrm{~m} / \mathrm{s}$ ).

\section{EXPERIMENTAL DETAILS}

\section{A. Materials}

In this work polyester resin and sheep wool fibre as matrix and reinforcement. The polyester resin and additional ingredients (MEKP \& CN) as catalyst and accelerator were brought from Chennai, Tamil Nadu, India. The Collected sheep wool fibre contains dust particles, it was washed and removed by water and dried at room temperature. The dried sheep wool fibre is cut into $20 \mathrm{~mm}$ of equal length and placed in a tray for fabrication of composite.

\section{B. Fabrication of Composite}

To develop the composite, sheep wool fibre and polyester resin are used as matrix and reinforcement material. By using compression moulding method the composite plates are developed. Initially, the mould is cleaned and applying wax over surface of the mould for easy removal of fabricated composite. The sheep wool fibres of $20 \mathrm{~mm}$ length are randomly arranged in the mould cavity $2 \%$ methyl ethyl ketone peroxide and $2 \%$ cobalt naphthalene as catalyst and accelerator is stirred properly in the polyester resin and poured on the mould cavity. Finally the mould is closed and compressed by using machine. Composites of three different $\mathrm{wt} \%$ (20 wt $\%, 30 \mathrm{wt} \%$ and $40 \mathrm{wt} \%$ ) as sheep wool fibre reinforced polyester composite are prepared by using same procedure. The compression loading are kept constant for proper curing at room temperature for 24 hours. The fabricated composite is cut into suitable dimensions for erosion test as per ASTM standards. The prepared specimen for erosion wear test is shown in Fig. 1. The detailed wt $\%$ of reinforcement for the erosion study is shown in Table 1 and Table II. shows the erosion control factors used to conduct the studies. 


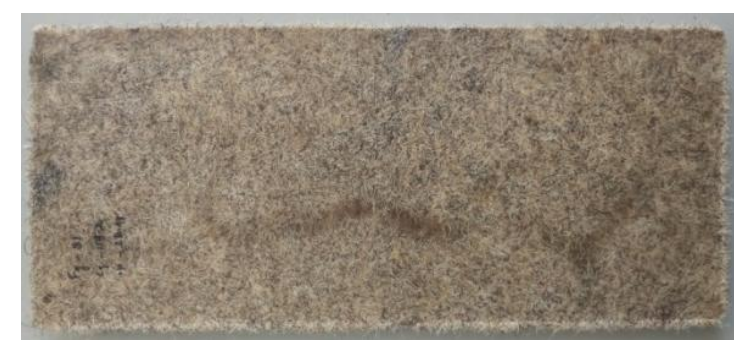

Fig. 1. Fabricated Composite

Table- I: Detailed composition of the specimen

\begin{tabular}{|c|c|}
\hline Composite & Composition \\
\hline CP1 & Polyester+20 wt\% Sheep wool fibre \\
\hline CP2 & Polyester+30 wt\% Sheep wool fibre \\
\hline CP3 & Polyester+40 wt\% Sheep wool fibre \\
\hline
\end{tabular}

Table- II: Erosion Test Parameters

\begin{tabular}{|c|c|c|c|}
\hline \multicolumn{2}{|c|}{ Fixed parameters } & \multicolumn{2}{|c|}{ Variable parameters } \\
\hline Erodent material & $\begin{array}{l}\text { Alumina } \\
\text { oxide }\end{array}$ & $\begin{array}{l}\text { Reinforcement } \\
\text { (wt\%) }\end{array}$ & 20,30 and 40 \\
\hline $\begin{array}{l}\text { Particle size of } \\
\text { erodent }(\mu \mathrm{m})\end{array}$ & 50 & \multirow{3}{*}{$\begin{array}{l}\text { Impingement angle } \\
\text { (degree) }\end{array}$} & \multirow{3}{*}{30,60 and 90} \\
\hline Time (mins) & 10 & & \\
\hline $\begin{array}{l}\text { Erodent } \\
\text { discharge rate } \\
(\mathrm{g} / \mathrm{min})\end{array}$ & 3.3 & & \\
\hline $\begin{array}{l}\text { Testing } \\
\text { Temperature }\end{array}$ & RT & \multirow{3}{*}{$\begin{array}{l}\text { Impact velocity } \\
(\mathrm{m} / \mathrm{s})\end{array}$} & \multirow{3}{*}{41,72 and 100} \\
\hline $\begin{array}{l}\text { Standoff } \\
\text { distance }(\mathrm{mm})\end{array}$ & 10 & & \\
\hline $\begin{array}{l}\text { Diameter of } \\
\text { nozzle }(\mathrm{mm})\end{array}$ & 3 & & \\
\hline
\end{tabular}

\section{RESULT AND DISCUSSION}

From the researchers investigations impact velocity, impingement angle, erodent size, shape, hardness and discharge rate, standoff distance and time have an important effect on erosion wear rate. This effect shows that a variation depends upon the testing of materials as ductile, brittle or semi-ductile. For brittle and ductile materials the erosion rate is maximum at an impingement angle of $30^{\circ}$ and $90^{\circ}$ and for semi ductile materials it was found that the erosion rate is maximum at angle of $60^{\circ}$. The delamination of fibres on surface of the materials is stop easily when increasing the erodent flow. The fact is increasing the striking speed of particle on the surface of material is the most important factors which leads to increase in wear rates, changing the angle of impingement should possess less wear rate as compare to speed variation. Besides striking speed, impingement angle and varying the size of erodent plays a vital role in increasing the rate of erosion. But, the effects of changes in direction of fibre leads to less wear rate when compared to other factors.

The most important parameters which influence erosive wear are impingement angle, impact velocity, erodent size, shape and discharge rate, standoff distance and time. The sequence of damage in fibre reinforced polymers due to erosive action. At the initial stage, material removal takes place in resin rich zones, further action which leads to breakage of fibres and laterally the fibre and matrix bond was damaged due to erosion.

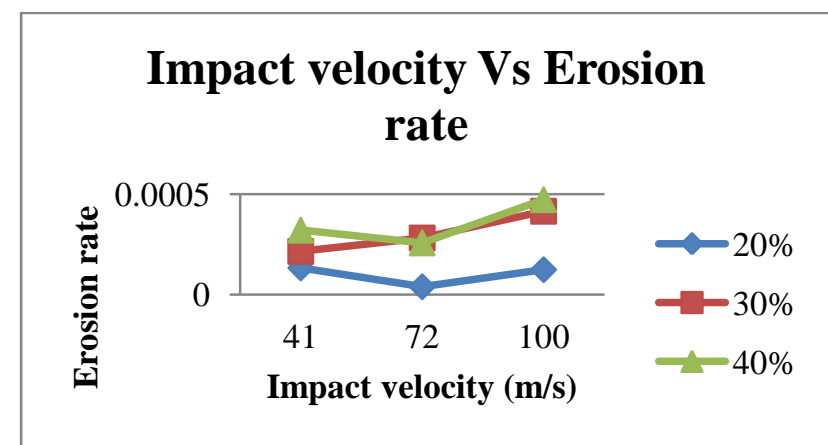

Fig. 2. Impact velocity Vs Erosion rate for varying wt\% of reinforcement

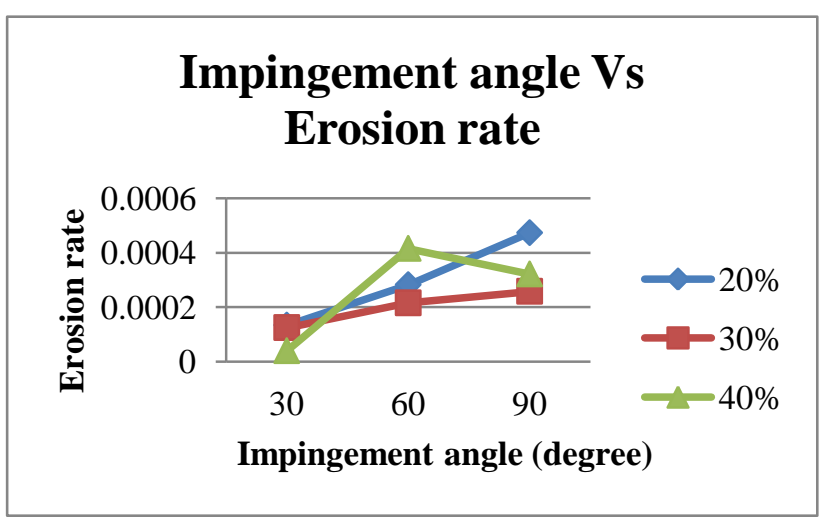

Fig. 3. Impingement angle Vs Erosion rate for varying wt \% of reinforcement

A graph is plotted to observe the changes in erosion behaviour of composites with various factors are change in impingement angle, with varying wt $\%$ of fibre at different impact velocity $(41 \mathrm{~m} / \mathrm{s}, 72 \mathrm{~m} / \mathrm{s}$ and $100 \mathrm{~m} / \mathrm{s})$; From the Fig. 2 . it is understand that increase in impingement angle increase the erosion rates with constant impact velocity. It is also noted that in addition to impingement angle in wt $\%$ of fibre increase the erosion rates. The similar kind of observation is also made in Fig. 3. shows that increase in striking speed increase the erosion wear rates with constant impingement angle. The other observation made from the Fig. 3. is in addition to striking speed increase in wt $\%$ of reinforcement decreases the erosion rates.

\section{CONCLUSION}

The following conclusions are made for the erosion performance of sheep wool reinforced polyester composites.

1) The sheep wool fibre reinforced polyester composites were successfully made with the help of compression moulding technique.

2) Increases the wt\% of reinforcement significantly alter the erosion performance of the composites.

3) In addition to impact velocity, increase in wt $\%$ of reinforcement decreases the erosion wear rates.

4) Impact velocity and impingement angle plays a significant role in increase the erosive wear rate of the composites.

5) Erosion wear behaviour of these composites improves with addition of reinforcement. It may be recommended for the application of light weight vehicles because of its nature as biodegradable and eco-friendly. 


\section{REFERENCES}

1. I. Finnie, Some reflections on the past and future of erosion, Wear; vol. 186, 187(1), pp. 1-10, 1995.

2. G. Sundararajan, M. Roy, Solid particle erosion behaviour of metallic materials at room and elevated temperatures, Tribol Int, vol. 30(5), pp. 339-59, 1997.

3. I. Mutlu,C. Oner, F. Findik, Boric acid effect in phenolic composites on tribological properties in brake linings, Mater Des, vol. 28, pp. 480-7, 2007

4. I. Mutlu,C. Oner, F. Findik, Wear performance of some phenolic composites with boric acid, Ind Lubricat Technol, vol. 59(1), pp. 38-45, 2007

5. S. Biswas, A. Satapathy, A study on tribological behavior of alumina-filled glass epoxy composites using Taguchi experimental design, Tribol Trans, vol. 53, pp. 520-32, 2010.

6. A. Patnaik, A. Satapathy, S.S. Mahapatra, R.R. Dash, Implementation of Taguchi design for erosion of fiber reinforced polyester composite systems with SiC filler, J Reinf Plast Compos, vol. 27(10), pp. 1093-111, 2008.

7. V.K. Srivastava, A.G. Pawar, Solid particle erosion of glass fiber reinforced flyash filled epoxy resin composites, Compos Sci Technol, vol. 66 , pp. 3021-8, 2006.

8. M. Cirino, R.B. Pipes, K. Friedrich, The abrasive wear behaviour of continuous fibre polymer composites, J Mater Sci, vol. 22, 2481-2492, 1987.

9. Q.H. Wang, Q.J. Xue, W.M. Liu, J.M. Chen, The friction and wear characteristics of nanometer SiC and PTFE filled PEEK, Wear, vol. 243, pp. 140-146, 2000.

10. S.S. Mahapatra, A. Patnaik, A. Satapathy, Taguchi method applied to parametric appraisal of erosion behavior of GF-reinforced polyester composites, Wear, vol. 265, pp. 214-22, 2008

11. A. Suresh, A.P. Harsha, M.K. Ghosh, Erosion studies of short glass fiber-reinforced thermoplastic composites and prediction of erosion rate using ANNs, J Reinf Plast Comp, vol. 29(11), pp. 1641-52, 2010.

12. T. Sinmazcelik, I. Taskıran, Erosive wear behaviour of polyphenylenesulphide (PPS) composites, Mater Des, vol. 28, pp. 2471-7, 2007.

13. V.K. Srivastava, Effects of wheat starch on erosive wear of E-glass fiber reinforced epoxy resin composite materials, Mater Sci Eng A, vol. 435, 436, pp. 282-7, 2006.

\section{AUTHORS PROFILE}

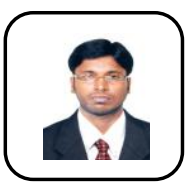

Mr. J. Manivannan completed his B.E. Mechanical Engineering in K.S.Rangasamy College of Technology, Tiruchengode. He has completed his M.Tech (CAD/CAM) in Kalasalingam University, Krishnankoil. $\mathrm{He}$ is serving as Assistant Professor in same institute and doing his research as part time mode. His area of research as performance studies on polymer matrix composites. He has published 4 Journal papers (Impact Factor and Scopus Indexed) and more than 15 International Conference papers.

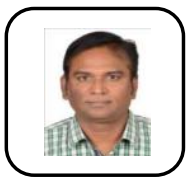

Dr. S. Rajesh completed his B. E in Mechanical Engineering and M.E. (CAD) from Alagappa Chettiar Government College of Engineering and Technology, Karaikudi, Ph.D (Machining of Metal of Matrix Composites) from Kalasalingam Academy of Research and Education, Krishnankoil in the year 2014, and thesis highly recommended by both the examiners. In the year 2018, I have received DST - AMT project for the worth of Rs. 25,72,400 and completed one IEDC project for the worth of Rs. 1,00,000. He has published more than 25 Journal papers (Impact Factor and Scopus Indexed) and more than 40 International Conference papers.

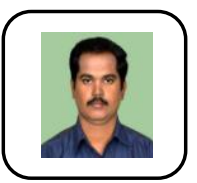

Dr. K. Mayandi received his B.E. (2007) in Mechanical Engineering and M.E. (2011) in Engineering Design from Anna University, Chennai and obtained the Ph.D (2016) from Kalasalingam University, Krishnankoil. He is working as an Associate Professor in the School of Automotive and Mechanical Engineering at Kalasalingam Academy of Research and Education, Krishnankoil, Madurai, India. His research interest on characterization of natural fibres and utilized the natural fibres as reinforcement with polymer composites materials for biodegradable applications. Recently focuses the research on fracture analysis of layered polymer composites materials and also involves the works on fabrication and testing of filament winding polymer composites tube for medium load applications areas. He has published 12 International Journals and 2 Book Chapters published in Elsevier and Wiley publications. 